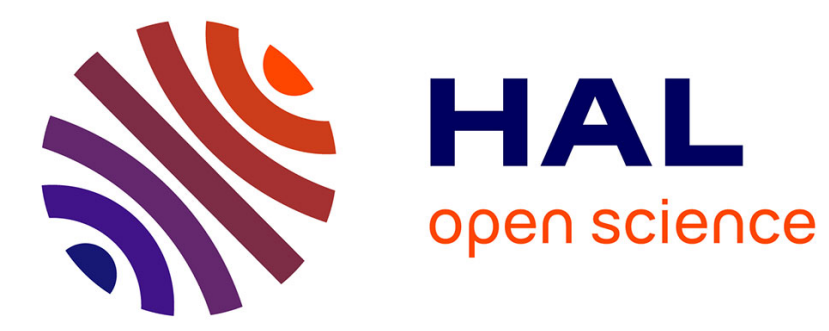

\title{
PLM Competencies Analysis Based on Industry Demand
}

Mourad Messaadia, Samir Ouchani, Anne Louis

\section{To cite this version:}

Mourad Messaadia, Samir Ouchani, Anne Louis. PLM Competencies Analysis Based on Industry Demand. 15th IFIP International Conference on Product Lifecycle Management (PLM), Jul 2018, Turin, Italy. pp.692-701, 10.1007/978-3-030-01614-2_63 . hal-02075606

\section{HAL Id: hal-02075606 https://hal.inria.fr/hal-02075606}

Submitted on 21 Mar 2019

HAL is a multi-disciplinary open access archive for the deposit and dissemination of scientific research documents, whether they are published or not. The documents may come from teaching and research institutions in France or abroad, or from public or private research centers.
L'archive ouverte pluridisciplinaire HAL, est destinée au dépôt et à la diffusion de documents scientifiques de niveau recherche, publiés ou non, émanant des établissements d'enseignement et de recherche français ou étrangers, des laboratoires publics ou privés.

\section{(c)(1)}

Distributed under a Creative Commons Attribution| 4.0 International License 


\title{
PLM Competencies Analysis Based on Industry Demand
}

\author{
Mourad Messaadia ${ }^{1}$, Samir Ouchani $^{2}$, and Anne Louis ${ }^{1}$ \\ ${ }^{1}$ CESI/LINEACT, Rouen, France \\ ${ }^{2}$ CESI/LINEACT, Aix En Provence, France \\ \{mmessaadia, souchani, alouis\}@cesi.fr
}

\begin{abstract}
Last decade recognizes a high job demand, more specialized trainings with very oriented jobs offers. This situation makes hiring and recruitments officers in the difficulty to select and find easily the appropriate candidate as well for candidates to choose the best practices and trainings to find later a respectable position. This work aims to help all actors in the job sector by modeling the Product Lifecycle Management (PLM) competencies and analyzing the demands especially in industry 4.0. First, the enterprises needs, in terms of skills, are identified through various job offers distributed on online media. Job offers are structured according to profile, geolocation and required competencies, etc. Then, the analysis is based on information retrieval and text mining through a statistical measure used to evaluate how important a competence to a job offer in a given collection. This contribution applies the Term Frequency Inverse Document Frequency (TF-IDF) to determine what skills in a corpus of job offers is the most requested in PLM jobs. This contribution addresses more than 1300 job offers, written in French, and posted in France during the period of (2015-2016). The offers cover more than $388 \mathrm{~K}$ words, from which 20 types of PLM job titles and 106 terms are related to the job competencies. The obtained results allow us to identify the most requested jobs, skills and classifying jobs and competencies for a better guidance of PLM job actors.
\end{abstract}

Keywords: PLM Competencies, PLM job offers, TF-IDF, Clustering.

\section{$1 \quad$ Introduction}

The industry sector, which is part of a globalized economy with high competitiveness requirements, is currently undergoing deep structural changes in its business model that is related principally to scientific, economic, demographic and societal factors. This change will, in the short or medium term requires new skills able to understand and to face the jobs searching and hiring challenges.

The roadmap for manufacturing 2.0 places human at the center of the organization [1]. Thereby, the development of the necessary human resources concerns the whole process of small and large industrial enterprises. For that, an enterprise should carry out a complete diagnosis of its business lines and the skills held by its employees [2], as well as tools (GPEC, eRH, etc.) already deployed in the context of human resources management (job repositories, job descriptions, interview schedules, etc.). Depending on its medium and long-term strategy and the context (economic, social, 
technological, regulatory, etc.), the enterprise projects future jobs and skills in order to measure the gaps with the existing one [1]. At this stage, the external support (specialized consultant) is often recommended to handle a part of this stage's tasks.

With the arrival of Industry 4.0, manufacturing processes will evolve and generate an increased technical and organizational complexity [3], which will involve significant challenges for manufacturing companies (SMEs). This issue will go beyond the financial investment needed to acquire new technologies to reach the human aspects. Effectively, one of major aspects facing the company is the skilled workforce at all levels, that are able to face the growing complexity of Industry 4.0 [4].

According to "Global Industry Analysts" prediction, the global market for PLM will reach 65.8 billion $\$$ by 2022. Further, PLM software market will grow to 20.41 billion \$ during 2019, with 7.4\% of annual Growth Rate [5]. However, it is announced that more than 25,000 PLM specialists are missing in Europe [6]. PLM adoption includes very extensive changes in organizational practices and requires new types of persons' skills and capabilities [7]. Investigations show that size of enterprise and human capital of the workforce, have an impact on PLM adoption [8]. As a consequence, it is mandatory to analyse PLM job offers and PLM competencies needed for industry.

The job offers analysis means analysing the content of the job offers and the competencies sought behind. For example the system proposed in [9] that is based on competence model permit to recommend potential candidates for an offer emitted by a recruiter. It relies on extracting the job title, skills and experience required for the posted position. Further, work in [10] focuses on job offer recommendation process based on user and job offer modeling.

PLM competencies mean developing a model based on a description of the competence concept. Erol et al. [4] developed a problem-competency framework based on three-dimensional: management, production process and type of competency. The competencies addressed in this model are personal, social, action and domain. R. Wittorsky [11] located a competence at the intersection of 3 fields: socialization and biography of the individual and the professional experience and training.

This paper is composed of four main sections. After introducing PLM problems and sketching our contribution, we provide an analysis of PLM competencies, a job offer structure and competencies extraction method. Then, Section 3 presents job offers analysis based on the developed model. Finally, we conclude the paper and hint the future directions.

\section{PLM Competencies analysis}

PLM adoption implies more collaboration between people in the same department, between the different departments of a company and between companies and their partners (supplier for example). PLM competencies (engineers, consultants etc.) will have a key role to play in Industry 4.0 evolution. The French employment association for executives (APEC) carried out a study according PLM job offers where it shows an increasing of PLM skills by $36 \%$ in only one year [12]. The work analysis 'PLM 
jobs' and its related competencies are grouped in three major steps as shown in Fig. 1. Herein, we develop each of steps: job offers preparation, competencies extraction, and competencies evaluation.

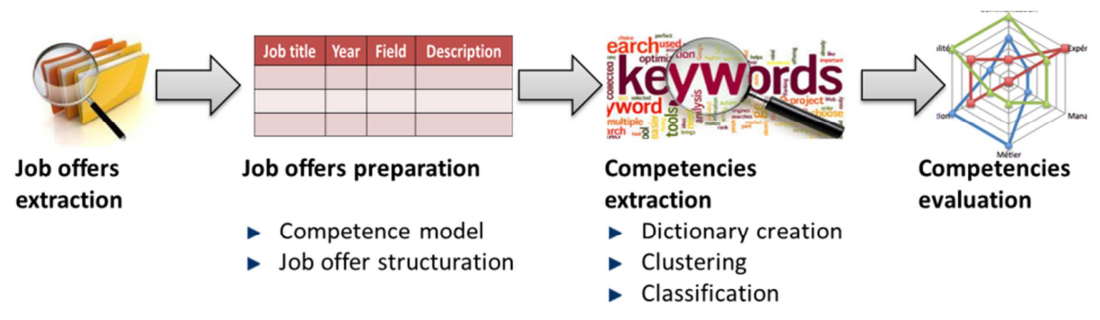

Fig. 1. Proposed approach

Initially, the jobs offers are presented in a textual form describing, the title, the jobs description, etc. To enhance the processing of the considered offer, we parse first step, the textual document, to extract a set of keywords following three steps [13]:

- Tokenisation: words are separated, by splitting the text at each whitespace and removing the special characters (punctuations, accents...). In this step we defined unique word for same words written in different ways. e.g. 3DExperience, 3DExperience and 3D Experience become 3DExperience.

- Words filtering: words that don't convey any information are removed, such as the determinants, or if it belongs to a list set beforehand [14]. This step allows us to only keep the needed words (tokens issued from tokenization phase) and then generate the dictionary.

- Words processing: reduce the word's list by excluding words having the same/close meaning (e.g. competence / competencies) [15].

\subsection{Proposed model}

To model the PLM competencies and their system management, we align within the existing modeling standards, especially UML. The proposed model is developed according to two main parts the competencies and job offers. Competencies modeling is addressed according to internal aspects such (to-know-how, to-know and to-knowwhom) presented in [16]. Job offers modeling is proposed according to online job postings analysis.

Fig. 2 shows the class diagram describing the competences and job offers model. We explain each class related to the competencies as follows.

- "Knowledge" represents everything that is learned by an initial or specific training which addresses: theoretical knowledge, knowledge about the existing on the environment in which a skill is fulfilled the procedural knowledge (procedures and operating methods related to the activity). 


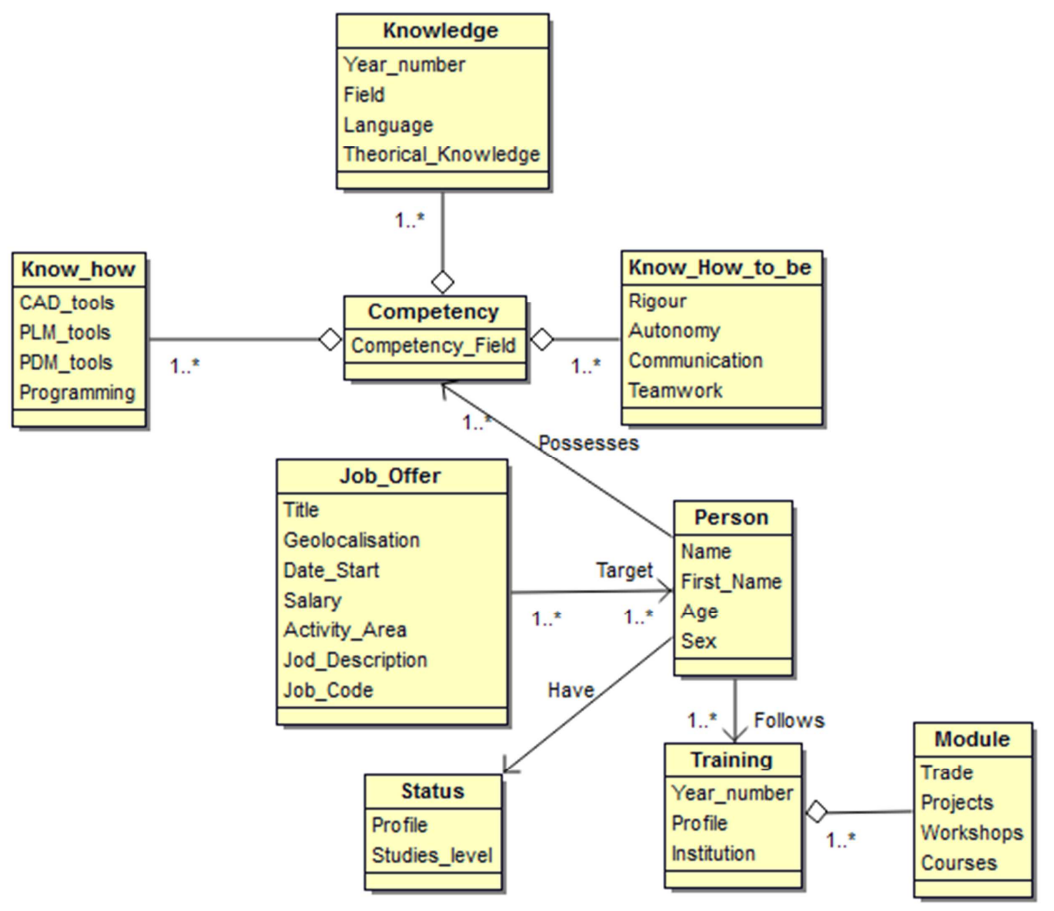

Fig. 2. Competencies Class Diagram Model

- "Know_how" is related to experience and operational capabilities and that means I know how to do it, I know how to do it and I can teach someone else to do it.

- "Know-How_to_be" represents an individual characteristic that allow adopting a particular behavior in a given situation. They combine relational skills (associated with cooperative behaviors), cognitive skills (intellectual operations of problem solving) and behaviors (personal qualities).

Each job offer targets one or more person with specific competences. Each person follows training, composed of one or more modules, and has a status describing his profile and study level (Fig. 2).

\subsection{Job offer structuration}

Job offer is a description of a vacant position in a job offer described in a textual document. This document is presented as a text and posted on recruitment websites (APEC, Indeed, Monster, etc.) in order to attract the appropriate candidate. The job offer is separated into several textual fields such title, company description, location, contract, study, experience, sector, and job category. The job adverts is described according two types of fields, unstructured which is purely textual and written in natural language, or structured with numbers such experience. 
Table 1. Data structuration.

\begin{tabular}{lll}
\hline Title & Structured & Unstructured \\
\hline & & $\ldots$ Position and missions: Enovia / CATIA \\
& V6 Functional Consultant: To participate in \\
PLM & Enterprise field; year; & $\begin{array}{l}\text { workshops and functional document speci- } \\
\text { Functional }\end{array}$ \\
Ponsultant & Salary; Place & $\begin{array}{l}\text { fications for digital models. Profile: } 2 \text { years } \\
\text { of experience minimum, Bilingual English } \\
\end{array}$ \\
& & $\begin{array}{l}\text { required (French oral / written) to begin for } \\
\text { mid-March, early April ... }\end{array}$ \\
\hline
\end{tabular}

In the structured data we have the enterprise field, year of job offer apparition, the position of the candidate, the occupation and the job location. The non-structured data contains the textual job offer description. Principally, the structured data will be used for the job offers analysis (non-structured).

\subsection{Competencies extraction}

A job offer is seen as a multiset of terms called "Bag of words", which is a set in which the same element can occur several times.

$$
T=\left\{T_{1}, T_{2}, \ldots, T_{n}\right\}
$$

A collection of " $n$ " documents and " $m$ " distinct terms can be represented as a matrix, which represents the document database.

$$
W=\left[\begin{array}{cccc} 
& T_{1} & \cdots & T_{m} \\
D_{1} & w_{11} & \cdots & w_{1 m} \\
\vdots & \vdots & \ddots & \vdots \\
D_{n} & w_{n 1} & \cdots & w_{n m}
\end{array}\right]
$$

Most of the methods of transforming text into Bag of Words can be divided into three main approaches. The first is a purely statistical approach based on the occurrence of terms like Term Frequency (TF) and Term Frequency-Inverse Document Frequency (TF-IDF) [17]. The second is a semantic based approach, which includes both Latent Semantic Analysis (LSA) and Latent Dirichlet Allocation (LDA) [18] methods. The third one is an alternative approach between both (all the methods of the N-gram family) [19].

The N-gram family is more adapted to word sequence analysis and LSA requires the order of words appearance and used for the semantic aspect of the sentence such synonyms detection. The TF-IDF is the most used method because it helps to weight the importance of a term within a document and its importance in a corpus, but requires the use of "bag of words". It also, allows avoiding the word filtering step.

In this work, TF-IDF is used for determining the relative frequency of competencies in job offers compared to the inverse proportion of that word over the entire doc- 
ument corpus. The calculation determines how relevant a given term is in a particular document. Terms that are common in a single or a small group of documents tend to have higher $w_{i, j}$ weight than common words such as articles and prepositions [17].

$$
w_{i, j}=t f_{i, j i} \times i d f_{i}=\frac{n_{i, j}}{\left\|d_{j}\right\|} \times \log \left(\frac{N}{d f_{i}}\right)
$$

Where (according to each job):

$$
\begin{aligned}
& t f_{i, j}=\text { frequency of apparition of } i \text { (term) in } j \text { (document) } \\
& n_{i, j}=\text { the number of occurrences of } i \text { (term) in } j \text { (document) } \\
& \left\|d_{j}\right\|=\text { the length of the document } \\
& d f_{i}=\text { number of job offers containing } i \text { term } \\
& N=\text { number of corpus (documents) }
\end{aligned}
$$

For our case study, we replace the length of the document $\left\|d_{j}\right\|$ by the length of the total competencies identified and $N$ is replaced by number job offers with same title. Thus, the $t f$ leads to a weighting proportional to the number of occurrences of a competence according to the set of competencies.

\section{Job offers analysis}

Based on (1300) job offers collected from APEC database for the period between (2015-2016), we extract the PLM job types from offers titles and then classified into 20 job categories (Fig. 3).

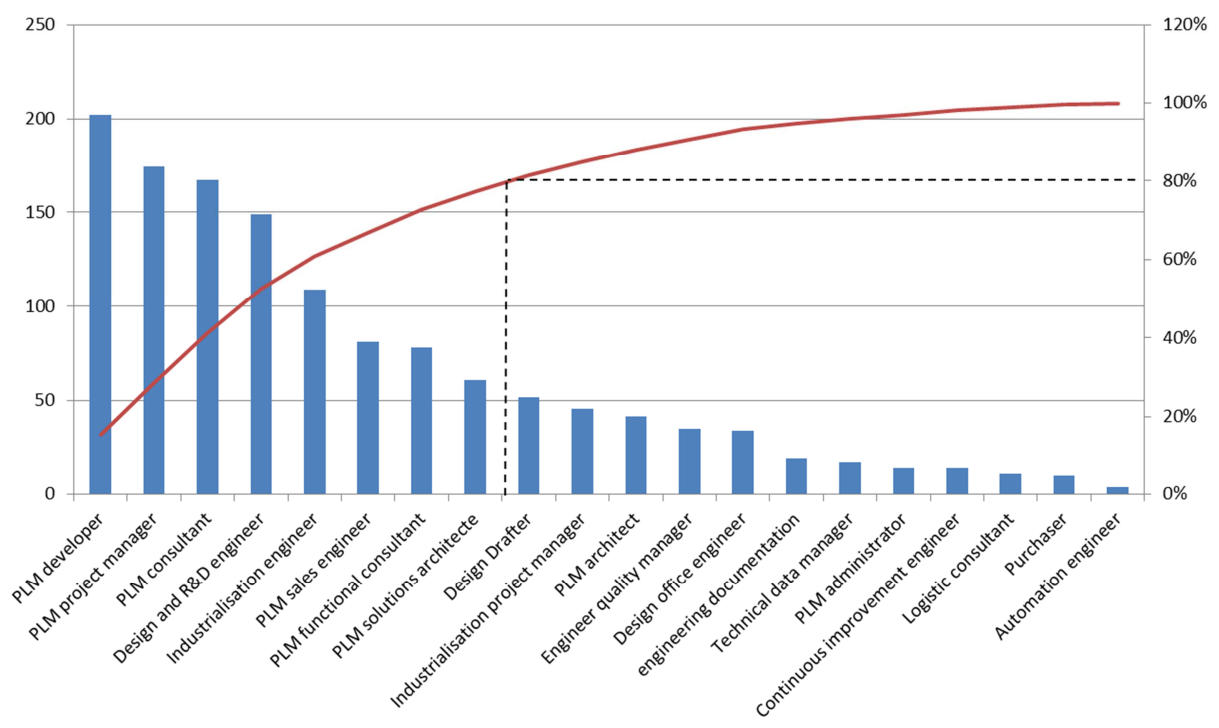

Fig. 3. Types of PLM job offer. 
The pareto diagram (Fig. 3) shows the frequently required jobs. We can see that 8 PLM jobs account for $80 \%$ of required job: PLM developer, PLM project manager, PLM consultant, design and R\&D engineer, industrialisation engineer, PLM functional consultant, and PLM solution architect.

The radar diagrams in (Fig. 4) give an overview of the frequently required competencies according to the PLM consultant job:

(a) Shows knowledge where computer science education competence is the most required then we find the level of engineer without requirement on the field of specialty. English seems important for this kind of job.

(b) Shows know how, where SAP is the most needed competence. This diagram is usefull if we need to classify PLM tools or PLM software owners. With CATIA, Dassault Systems Company is just after Teamcenter then Windchill of PTC. For PLM consultant the computer science level is characterized by JSP, SQL, C++ and java competencies.

(c) Shows the how know to be, where relational and rigorous for PLM consultant job and for the eight PLM jobs identified in (Fig. 3). Listening, communication and responsible are also required for this kind of job.
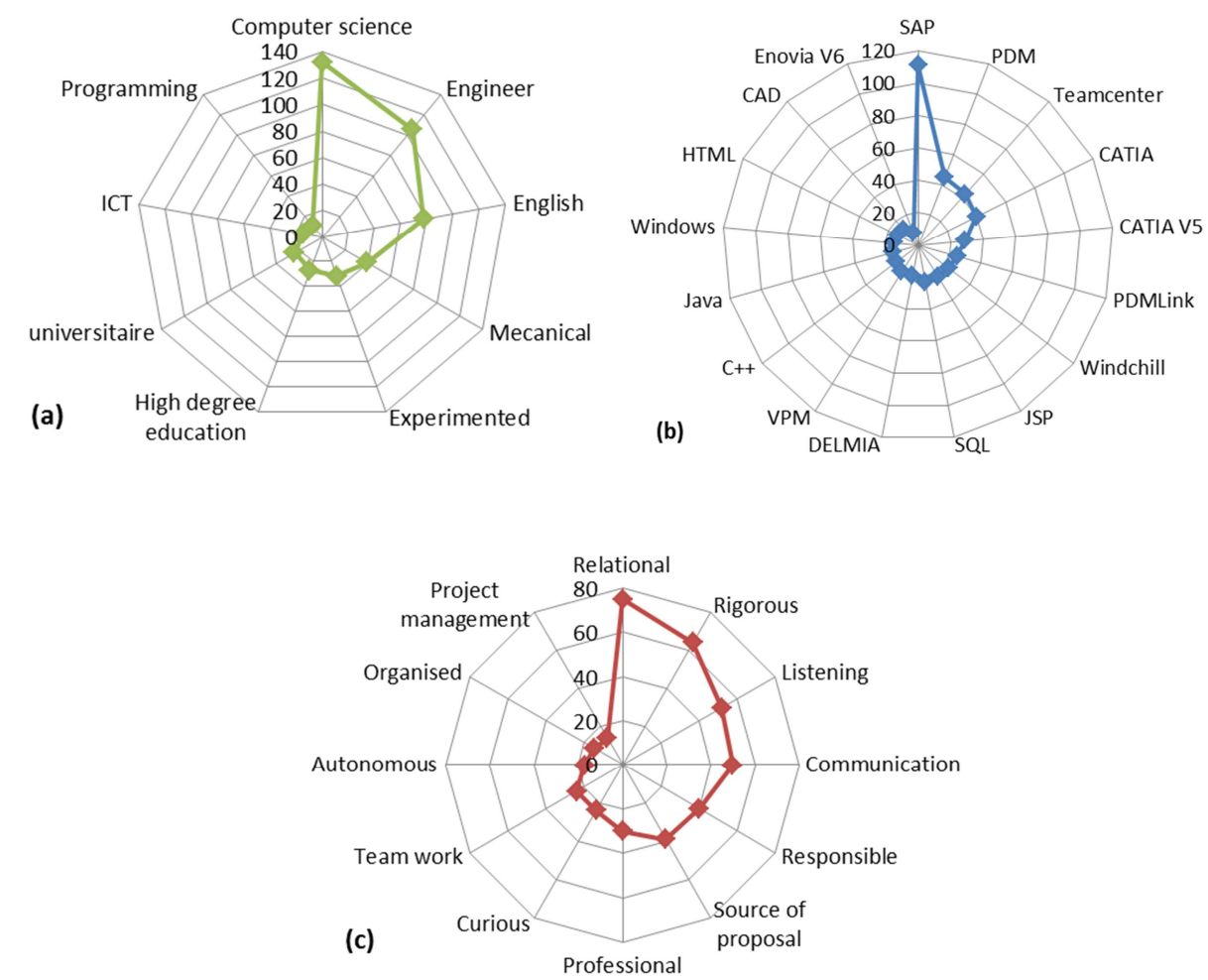

Fig. 4. Frequently required competencies for PLM consultant job: (a) knowledge, (b) know how, and (c) know how to be. 
The same analysis is conducted for each PLM job, where we analysed the competence required frequency. (Fig. 5) shows the pareto diagram of PLM developer job. Among the most requested competencies $(80 \%)$ we find programming competencies (Java, $\mathrm{C}++$, PHP), Database (SQL, Server), product data management (PDM and PDMLink), PLM software (SAP, windchill and team center) and CAD (CATIA).

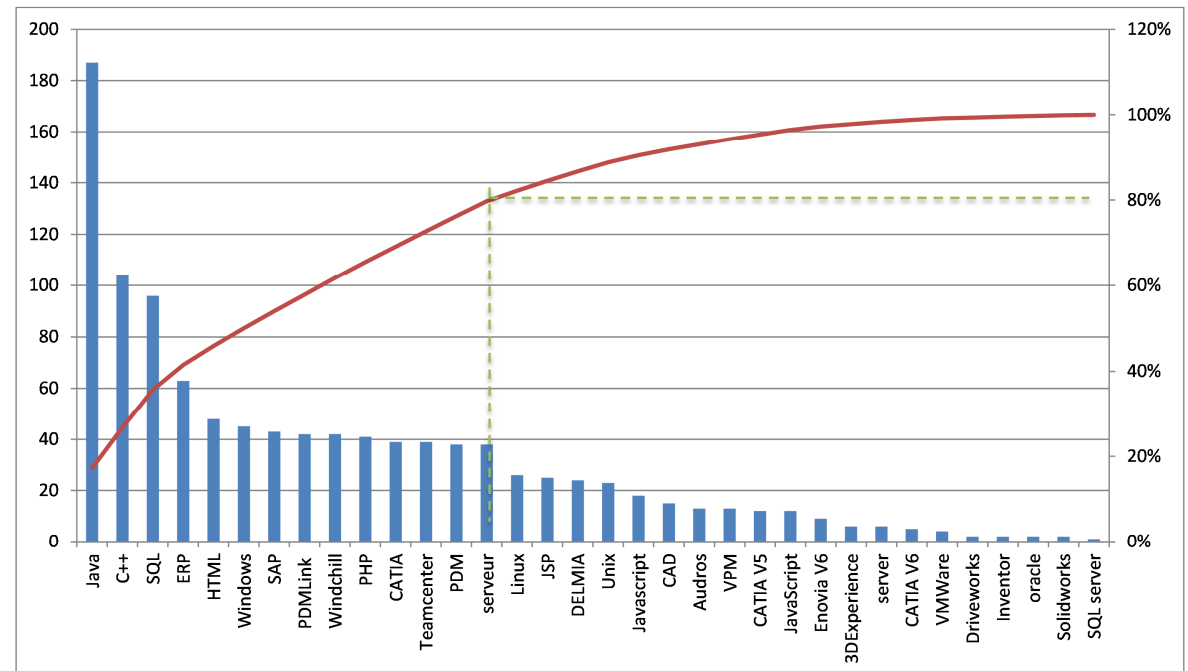

Fig. 5. Required competencies for developer job

During our analysis, the ERP often appeared in job offers. As showed in (Fig. 5) the ERP frequency appears before PLM tools. This can be explained by the lack of maturity of the PLM, which pushes the recruiters to begin by introducing the ERP which seems an alternative for PLM. This can be also seen as a need to train people to PLM solutions.

The TF-IDF deployment gives a great vision of competencies needed. However this method is based on an existing dictionary of existing competencies. If we want to identify new competencies (don't existing in the dictionary) in automatic way, we will have to go to other methods such as N-gram family.

\section{Conclusion}

To help job actors in Industry 4.0, we developed a PLM modeling and analysis framework. The latter model describes enterprises needs where job offers are structured according to profile, geolocation and required competencies, etc. Further, the analysis of the model relies to the information retrieval and text mining to evaluate how important a competence to a job offer in a given collection. The framework enhances TF-IDF to determine what skills in a corpus of job offers. The effectiveness of the framework has been shown on more than 1300 job offer. The obtained results 
allowed us to identify the most requested jobs, skills and classifying jobs and competencies for a better guidance of PLM job actors.

We would like to extend our work in different directions. First, we will include the level of experience needed in order to guide the level of deepening of knowledge during training. Methods such N-gram family will be explored. Then, we will evaluate distances between different types of PLM jobs across skill types. Further, experiment the framework with different sectors and datasets.

\section{Acknowledgement}

This work is supported by the French Government's Program "Investments for the Future". Acknowledgement is made to APEC for the job offers database.

\section{References}

1. ICT for Manufacturing The ActionPlanT Roadmap for Manufacturing 2.0, https://setis.ec.europa.eu/energy-research/sites/default/files/static-

projects/files/roadmap.pdf

2. Thoben, K. D., Wiesner, S., \& Wuest, T.: Industrie 4.0" and smart manufacturing-a review of research issues and application examples. Int. J. Autom. Technol, 11(1). (2017).

3. Schuh, G., Potente, T., Varandani, R., \& Schmitz, T.: Global Footprint Design based on genetic algorithms-An "Industry 4.0" perspective. CIRP Annals-Manufacturing Technology, 63(1), 433-436. (2014).

4. Erol, S., Jäger, A., Hold, P., Ott, K., \& Sihn, W.: Tangible Industry 4.0: a scenario-based approach to learning for the future of production. Procedia CIRP, 54, 13-18. (2016).

5. https://www.marketsandmarkets.com/PressReleases/quality-lifecycle-managementsoftware.asp, last accessed 2018/01/29.

6. Jacquesraud Homepage, http://www.jacquesraud-consulting.com/fr/industrie-4-0-un-defipour-trouver-les-competences-plm/

7. Kärkkäinen H, Pels H, Silventoinen A.: Defining the customer dimension of PLM maturity. In: Rivest L, Bouras A, Louhichi B (eds) Product lifecycle management. Towards knowledge-rich enterprises, vol 388. Springer, Heidelberg, pp 623-634. (2012).

8. Messaadia, M., Benatia, F., Baudry, D., \& Louis, A.: PLM Adoption Model for SMEs. In IFIP International Conference on Product Lifecycle Management (pp. 13-22). Springer, Cham. (2017).

9. Casagrande, A., Gotti, F., \& Lapalme, G. : Cerebra, un système de recommandation de candidats pour l'e-recrutement. In AISR2017. (2017).

10. Diaby, M. : Méthodes pour la recommandation d'offres d'emploi dans les réseaux sociaux (Doctoral dissertation, Sorbonne Paris Cité). (2015).

11. Wittorski, R. : De la fabrication des compétences. - Education Permanente, $\mathrm{n}^{\circ} 135 \mathrm{La}$ compétence au travail. - pp. 57-70. (1998).

12. APEC - Tendance métiers dans l'industrie : Le PLM, ISBN 978-2-7336-1030-5, (2017).

13. Sebastiani, F.: Machine learning in automated text categorization. ACM computing surveys (CSUR), 34(1), 1-47. (2002).

14. Leskovec, J., Rajaraman, A., \& Ullman, J. D.: Mining of massive datasets. Cambridge university press. (2014). 
15. Liu, H., Christiansen, T., Baumgartner, W. A., \& Verspoor, K.: BioLemmatizer: a lemmatization tool for morphological processing of biomedical text. Journal of biomedical semantics, 3(1), 3 . (2012).

16. Girodon, J. : Proposition d'une approche d'amélioration des performances des organisations par le management opérationnel de leurs connaissances et compétences. Ph.D. thesis, Université de Lorraine. (2015).

17. Ramos, J.: Using tf-idf to determine word relevance in document queries. In Proceedings of the first instructional conference on machine learning (Vol. 242, pp. 133-142). (2003).

18. Blei, D. M., Ng, A. Y., \& Jordan, M. I.: Latent dirichlet allocation. Journal of machine Learning research, 3(Jan), 993-1022. (2003).

19. Kešelj, V., Peng, F., Cercone, N., \& Thomas, C.: N-gram-based author profiles for authorship attribution. In Proceedings of the conference pacific association for computational linguistics, PACLING (Vol. 3, pp. 255-264). (2003). 